\title{
The Role of Dimethoate and UV-B on Skin of Wistar Rats
}

\author{
TANIA RITA MORENO DE OLIVEIRA FERNANDES ${ }^{1}$, CELINA TIZUKO FUJIYAMA OSHIMA ${ }^{2}$, \\ LEONARDO CARDILI ${ }^{2}$, DANIEL ARAKI RIBEIRO ${ }^{3}$, \\ MARCELO SOUZA SILVA ${ }^{2}$, JULIANA PEDROSA KORINFSKY ${ }^{1}$ and HÉLIO PLAPLER ${ }^{4}$ \\ ${ }^{1}$ Department of Pathology, Federal University of Vale do São Francisco, Petrolina, Brazil; \\ ${ }^{2}$ Department of Pathology, ${ }^{3}$ Department of Biosciences, ${ }^{4}$ Department of Surgery, \\ Federal University of São Paulo, Sao Paolo, Brazil
}

\begin{abstract}
Background/Aim: The pesticide dimethoate (O-dimethyl-S- Nmethylcarbamoylmethyl phosphorodithioate) is able to induce severe acute toxicity in living organisms. The aim of this study was to evaluate the effects of ultraviolet radiation, alone or combined with exposure to dimethoate, on the rat skin. Materials and Methods: A total of 38 Wistar female rats (Rattus norvegicus albinus), were distributed into four groups: $A(n=9)$ control group, $B(n=10)$ exposed to ultraviolet- $B$ radiation $(U V-B), C(n=10)$ exposed to $U V-B$ followed by application of dimethoate $(U V-B+A G R O)$ and group $D(n=9)$ exposed to dimethoate $(A G R O)$. Histological examination of the tissues, as well as immunohistochemistry for cleaved caspase 3, Ki-67 and COX-2 expression were performed to all groups. Results: Animals submitted to UV$B$ exhibited hyperkeratosis with moderate cell atypia. Regarding exposure to $U V-B+A G R O$, the animals presented hyperkeratosis and atrophy, whereas in animals exposed to $A G R O$, only atrophy was noticed. The immunohistochemical results on skin revealed that $U V B, A G R O$ and $U V B+A G R O$ decreased cleaved caspase 3 and Ki-67 expression when compared to the control group $(p<0.05)$. COX-2 expression decreased to UVB or AGRO groups compared to controls $(p<0.05)$. Conclusion: $U V-B$ or AGRO exposure is able to induce histopathological changes and altered expression of cleaved caspase-3 and Ki-67 in rat skin, thus being categorized as a risk condition for skin carcinogenesis.
\end{abstract}

According to the International Agency for Research on Cancer (IARC), occupational exposure is the main form of human contact with carcinogens, such as pesticides and

Correspondence to: Prof. Daniel A. Ribeiro, Department of Biosciences, Federal University of Sao Paulo, UNIFESP, Rua Silva Jardim, 136, Room 332, Vila Mathias, Santos - SP, 11050-020, Brazil. Tel: +55 1332290156, e-mail: daribeiro@unifesp.br

Key Words: Dimethoate, pesticide, skin, UV-B, rat, apoptosis, cell proliferation. ultraviolet (UV) radiation (1). Work-related neoplasms are found in some organs, such as skin, lungs, stomach and bladder, among others, being directly absorbed or even eliminated from various carcinogenic agents (2).

The National Cancer Institute in Brazil estimated in 2016 about 596,000 new cases of cancer, of which non-melanoma skin cancer is the most common $(180,000)$. This is the most frequent type of human cancer and shows an increase in its incidence in recent years, becoming a growing public health problem worldwide (3). On the other hand, melanoma skin cancer has a high lethality, but its incidence is low, affecting 5,670 new cases annually (3).

Occupational exposure to UV radiation is a known risk factor for skin cancer (4). The action of UV radiation on the skin is a complex process that is associated with chemical and morphological changes, such as formation of reactive oxygen species, histochemical changes of different severities, thickening of the prickly layer and rectification of the basal layer of the epidermis. It also activates components of the cutaneous immune system and the release of inflammatory mediators by direct activation of keratinocytes and suppression of Langhans cells (5). DNA is one of the major molecules that absorbs UV radiation and undergoes several mutations that can subsequently result in malignant transformations of the eukaryotic cell (6). It has been demonstrated that continuous exposure to arsenic and others pesticides, ionizing radiation and chronic inflammation of the skin contribute to carcinogenesis as well (7). Epidemiological studies suggest a cause-effect relationship between malignant dermal neoplasms and exposure to pesticides in the work environment (8).

Pesticides are considered extremely relevant to the model of agricultural development of Brazil, with the country being the largest consumer of these products in the world up to now (9). The genotoxicity of these compounds is caused by means of adducts, oxidative alterations or even breaking of the DNA molecule, modifying qualitatively and quantitatively the genetic status (9). At high doses, pesticides increase DNA replication and cell proliferation, which can give rise to 
neoplastic cells; the target organ depends on the route of absorption and metabolization, while environmental factors, and factors inherent to the individual play a pivotal role in genomic instability (10).

Organophosphorus compounds are absorbed from the body through oral, respiratory, and cutaneous routes and can easily cross epithelial, dermal, and respiratory cell membranes due to their lipophilic structures (11). These compounds are distributed throughout the body, particularly in the fatty tissues, and their rapid degradation generally inhibits their accumulation (11).

Particularly, the insecticide dimethoate (O-dimethyl-SNmethylcarbamoylmethyl) phosphorodithioate and molecular formula C5H12NO3PS2) is able to induce severe acute toxicity according to the Hazard Classification System (ABNT-NBR 14725 - Part 2: 2009) on living organisms. In fact, some authors have postulated that dimethoate may cause dermatitis and sensitization in close contact with skin $(12,13)$. However, there are no reports investigating the harmful effects induced by dimethoate combined with UV on skin carcinogenesis so far.

The aim of this study was to evaluate the effects of UV, alone or combined with exposure to dimethoate, on the skin of Wistar rats.

\section{Materials and Methods}

Animals and experimental design. The study was approved by the Animal Ethics Committee at Federal University of Vale do Sao Francisco (UNIVASF) ( $\left.{ }^{\circ} 0015 / 120215\right)$, and Federal University of Sao Paulo (UNIFESP) ( ${ }^{\circ}$ 6407040516). It was an experimental study, which employs an animal model aligned to a follow-up study. A total of 38 Wistar female rats (Rattus norvegicus albinus), 3 months old, and average weight of $200 \pm 30 \mathrm{~g}$ was used. The time period of performance and observation of the animals was 15 weeks. This time was determined by considering previous studies published in the literature (14-16). The animals were distributed into four study groups, as follows: A $(n=9)$ control group, B $(n=10)$ exposed to ultraviolet-B radiation (UV-B), $C(n=10)$ exposed to UV$\mathrm{B}$ followed by application of dimethoate (UV-B+AGRO), and group $\mathrm{D}(\mathrm{n}=9)$ exposed to dimethoate only (AGRO).

Pesticide application. The pesticide under study was dimethoate (Agritoato $400^{\circledR}$ ). The chemical name is O, O-dimethyl-S(Nmethylcarbamoylmethyl) phosphorodithioate and molecular formula C5H12NO3PS2. For exposure to UVR-B and pesticide, the animals had a $3 \times 3 \mathrm{~cm}$ area of fur removed from their backs each three days, according to experiments conducted by Tang et al. (16). A solution containing the organophosphate "Agritoato ${ }^{\circledR}$ " diluted in distilled water containing $0.75 \mathrm{ml}$ of the pesticide for each $500 \mathrm{ml}$ of water, was applied topically to the back of the animals of group $\mathrm{C}$ and $\mathrm{D}$ three times a week, on non-consecutive days, using a wood stamp with a sponge on its end, measuring $6 \times 4 \mathrm{~cm}$, for a period of 15 weeks.

UV radiation. An UV-B lamp model G15T8E (UV-BRAVO, Bravoluz Lâmpadas Especiais ${ }^{\circledR}$, Curtiba, Brazil) with a wavelength of 280-360 nm (peak at 305-310 nm) and, power of $9 \mathrm{~J} / \mathrm{s}(\mathrm{W})$, which does not produce thermal alteration, was used. The rats from group A and B were submitted to exposure for $60 \mathrm{~s}, 3$ times a week, on non-consecutive days, on the same days of the pesticide application. The period of exposure to UV-B was based on the power of the lamp and the minimum time to obtain two times the Minimal Erythema Dose at the animal's skin (16). At the end of the experiment, 24,300 J of total energy for each animal were obtained as described elsewhere (14-16).

Microscopic analysis. For the resection of dermatological lesions (altered skin areas), the animals were euthanized under anesthesia, using a solution of ketamine hydrochloride $(60 \mathrm{mg} / \mathrm{ml})$ and xylazine hydrochloride $(18 \mathrm{mg} / \mathrm{ml})$. Skin tissues were resected, processed, and stained by the hematoxylin and eosin (H\&E) method. The following parameters were examined: hyperkeratosis, parakeratosis, cellular atypia, hypogranulosis, epidermal atrofia, spongiosis, and apoptosis. Apoptosis in skin tissue was evaluated as recommended by Elmore et al. (17).

Immunohistochemistry. To confirm the histopathological changes induced by UV and/or dimethoate, the expression of Ki-67 (proliferation activity), cleaved caspase-3 (apoptosis), and COX-2 (inflammation) was examined by immunohistochemistry in rat skin. The method was manually performed using the EnVision FLEX+, Mouse, High pH (Link) (Dako, Copenhagen, Denmark) and the Novolink (Novocastra Laboratories, Newcastle, UK) polymers according to the manual from the manufacturer. The EnVision polymer conjugate was used for the detection of mouse anti-COX 2 (C0X-2- D12) (Santa Cruz Biotechnology) (1:150) and mouse antiKi67 (MIB-1) (Novocastra) (1:30) antibodies, while Novolink for the cleaved rabbit polyclonal anti-caspase3 (Cell Signalling) (1:200).

Immunohistochemical data analysis. For the analysis, the Nikon optical microscope model Eclipse E600 was used. The percent expression of each marker was evaluated in 10 fields of $400 \times$ magnification and the semi-quantitative scoring system was used. For this purpose, a numerical scoring system with two categories was used. First, the number of immunoreactive cells was classified as 0 or negative (no immunoreactive cells or $<10 \%$ immunoreactivity), 1 (10 to $25 \%$ ), 2 (25 to $<50 \%$ ) and 3 (>50\% immunoreactivity). These values correspond to category A. In category B, the intensity of immunostaining was categorized as 0 or negative, 1 (no or weak immunostaining), 2 (moderate) and 3 (strong). After that, the numerical data from categories A and B were multiplied, resulting in an immunoreactive score ranging from 0 to 9 , with $0-3$ considered negative and 4-9 positive (18). All results were expressed to percentage (\%).

Statistical analysis. All data were evaluated by Fischer's exact test. Statistical analyses were performed using the statistical program $\mathrm{R}$ version 3.0.2. (www.r-project.org). All $p$-values $<0.0$ were considered statistically significant.

\section{Results}

Microscopic findings. In the control group, none of the animals presented microscopic changes within the scope of this investigation. In Group B (UV-B exposed rats), we observed hyperkeratosis and parakeratosis in all the animals; and 8 animals exhibited cellular atypia and hypogranulosis. Spongiosis and apoptosis were also observed in 5 animals. 
Table I. Distribution of variables analyzed in microscopic slides from animals exposed to dimethoate (AGRO) and ultraviolet radiation (UV-B).

\begin{tabular}{|c|c|c|c|c|}
\hline & $\begin{array}{c}\text { Control } \\
(n=9) \\
n\end{array}$ & $\begin{array}{c}\text { UV-B } \\
(\mathrm{n}=10) \\
\mathrm{n}\end{array}$ & $\begin{array}{c}\text { UV-B+AGRO } \\
(\mathrm{n}=10) \\
\mathrm{n}\end{array}$ & $\begin{array}{c}\text { AGRO } \\
(\mathrm{n}=9) \\
\mathrm{n}\end{array}$ \\
\hline \multicolumn{5}{|c|}{ Hyperkeratosis } \\
\hline No & 9 & & 2 & $9 * *$ \\
\hline Yes & - & $10 *$ & $8^{*}$ & - \\
\hline \multicolumn{5}{|c|}{ Parakeratosis } \\
\hline No & 9 & - & 2 & $8 * *$ \\
\hline Mild & - & 3 & $4^{*}$ & - \\
\hline Moderate & - & $4^{*}$ & 2 & - \\
\hline Severe & 1 & 3 & 2 & 1 \\
\hline \multicolumn{5}{|c|}{ Cellular atypia } \\
\hline No & 9 & 2 & $6^{*}$ & $9 * *$ \\
\hline Mild & - & - & 4 & - \\
\hline Moderate & - & $5^{*}$ & - & - \\
\hline Severe & - & 3 & - & - \\
\hline \multicolumn{5}{|c|}{ Hypogranulosis } \\
\hline No & 9 & 2 & 4 & $9 * *$ \\
\hline Yes & - & $8^{*}$ & $6^{*}$ & - \\
\hline \multicolumn{5}{|c|}{ Epidermal atrophia } \\
\hline No & 9 & $8^{*}$ & $7^{*}$ & - \\
\hline Yes & - & 2 & 3 & $9 *, * *$ \\
\hline \multicolumn{5}{|l|}{ Spongiosis } \\
\hline No & 9 & 5 & 6 & $9 * *$ \\
\hline Yes & - & $5^{*}$ & $4 *$ & - \\
\hline \multicolumn{5}{|l|}{ Apoptosis } \\
\hline No & 9 & 5 & 4 & 9 \\
\hline Mild & - & $5^{*}$ & $5^{*}$ & - \\
\hline Severe & - & - & 1 & - \\
\hline
\end{tabular}

${ }^{*} p<0.05$ when compared to control group; $* * p<0.05$ when compared to UV-B or UVB+AGRO groups.

In regard to UV-B+AGRO exposure, a total of 8 of the animals presented hyperkeratosis, and 2 specimens exhibited parakeratosis. Four animals in this group presented spongiosis and 6 rats presented apoptosis. It was also observed that atrophy was detected to three animals only. In the group D, atrophy of the skin was evident in all animals evaluated in this setting. Hyperkeratosis, parakeratosis, cellular atypia, hypogranulosis or spongiosis were not detected in this group.

Hyperkeratosis $(p<0.001)$, parakeratosis $(p<0.001)$ cellular atypia, $(p<0.001)$, hypogranulosis $(p<0.001)$, and spongiosis $(p=0.005)$ were more frequent in the UV-B and UV-B+AGRO groups, when compared to the AGRO and control groups. Epidermal atrophy was more frequent in the AGRO group when compared to the control, UV-B or UV$\mathrm{B}+\mathrm{AGRO}$ groups $(p<0.001)$. Regarding apoptosis, it was more frequent in the UV-B and RUV-B+AGRO groups when compared to the AGRO group ( $p=0.022)$. These results are summarized in Table I.
Table II. Expression of cleaved caspase-3, Ki-67, and COX-2 in rats exposed to diamethoate $(A G R O)$ and ultraviolet radiation $(U V-B)$, alone or in combination.

\begin{tabular}{lcccc}
\hline & $\begin{array}{c}\text { Control } \\
(\mathrm{n}=9) \\
\mathrm{n}\end{array}$ & $\begin{array}{c}\text { UV-B } \\
(\mathrm{n}=10) \\
\mathrm{n}\end{array}$ & $\begin{array}{c}\text { UV-B+AGRO } \\
(\mathrm{n}=10) \\
\mathrm{n}\end{array}$ & $\begin{array}{c}\text { AGRO } \\
(\mathrm{n}=9) \\
\mathrm{n}\end{array}$ \\
\hline Cleaved caspase-3 & & & & \\
$0-3$ & 8 & 0 & 0 & 0 \\
$4-9$ & 1 & $10^{*}$ & $10^{*}$ & $9^{*}$ \\
Total & 9 & 10 & 10 & 9 \\
Ki-67 & & & & \\
$0-3$ & 8 & 1 & 1 & 3 \\
$4-9$ & 1 & $9^{*}$ & $9^{*}$ & $6^{*}$ \\
Total & 9 & 10 & 10 & 9 \\
COX-2 & & & & \\
$0-3$ & 9 & 4 & 9 & 7 \\
$4-9$ & - & $6^{*}$ & 1 & $2^{*}$ \\
Total & 9 & 10 & 10 & 9 \\
\hline
\end{tabular}

$* p<0.05$ when compared to negative control.

Immunohistochemistry. None of the control group animals expressed COX-2, while one animal demonstrated immunopositivity for Ki-67 and cleaved caspase- 3 only. The animals in the UV-B group were positive for all markers investigated in this study. More specifically, cleaved caspase-3 $\quad(p=0.011), \mathrm{Ki}-67 \quad(p<0.001)$, and COX-2 $(p<0.001)$ were significantly increased in the UV-B group, compared to the control group. Regarding the UV-B+AGRO group, all animals were positive for cleaved caspase- 3 ( $p=0.011$, compared to the control group), and 9 animals for Ki-67 ( $p<0.001$, compared to the control group), whereas only one was positive for COX-2 ( $p>0.05$, compared to the control group).

In the group exposed to dimethoate only, all animals expressed positivity for the cleaved caspase-3 $(p=0.011)$ when compared to negative control. Regarding Ki-67 expression, a total of six animals expressed the proliferative marker $(p<0.001)$, and two animals expressed COX-2 $(p<0.001)$. The results demonstrated that groups B, C, and D expressed more cleaved caspase-3 $(p=0.011)$ and Ki-67 $(p<0.001)$ compared to negative control. These findings are summarized in Table II.

\section{Discussion}

In response to UV-B, all animals presented moderate focal or multifocal parakeratosis-like hyperkeratosis, which, when associated with cellular atypia and apoptosis, may be a marker for skin carcinogenesis (19). Skin cancer may be produced by UV action on epidermal keratinocytes due to the production of genotoxicity and DNA damage, directly or 
through reactive oxygen species (ROS), activation of oncogenes and inactivation of tumor suppressor genes (19).

Following the multi-step of skin carcinogenesis, the epidermis may present atrophic, of normal or acanthotic thickness and, in most cases, there is a decrease of the granular layer in the areas underlying the parakeratosis, as described by Smoller et al. (20). This is consistent with our findings animals submitted to UV-B and UV$\mathrm{B}+\mathrm{AGRO}$. Some dermatoses, including contact dermatitis, urticaria, erythema multiforme, gray dermatosis, porphyria cutanea tarda, carcinoid syndrome, Bowen's disease (squamous cell carcinoma in situ), multiple basal and squamous cell carcinomas, and melanoma, are described as caused by pesticides (21). In this study, we also found histopathological evidence (spongiosis) characterized as contact dermatitis in animals submitted to UV-B and UVB+AGRO (40\%).

All groups showed positivity for cleaved caspase-3, except for the control group. In light of these results, we have shown that both exposure to UV-B and dimethoate, alone or in combination, induced intense apoptosis in rat skin. It has been established that UV radiation induces genetic damage by means of generation of reactive oxygen species. By eliminating these damaged cells, apoptosis, induced via caspase-3 activation, plays a crucial role for preventing skin carcinogenesis $(22,23)$.

Regarding Ki-67, UV-B exposure to rat skin was able to increase ki-67 immunoexpression when compared to control. This is agreement with others (24). Dimethoate also increased cell proliferation in rat kin. The combination of dimethoate and UV-B showed similar values when compared to UV-B only. These results suggest that skin exposure to pesticides may constitute an important factor that induces cell proliferation and neoplasias.

The catalytic activity of COX-2 results in the production and potentiation of DNA damage by free radicals. The combination of these effects contributes to permanent damage to genomic DNA and cell differentiation. Studies that investigated the presence of this enzyme in normal skin and in non-melanoma cutaneous neoplasms, revealed that it was not expressed in healthy skin, but it was strongly expressed in actinic keratosis, and Bowen's disease (25). Jiao et al., similarly to our experimental model, used UV lamps in the 280-400 nm range to irradiate SKH-1 mice 3 times a week and found strong expression of COX-2 in epithelial cells of these animals after a single irradiation with UV-B (26). Another study demonstrated COX-2 overexpression in human keratinocytes irradiated by UV-B, confirming the correlation of this exposure with the increase in COX-2 positivity (27). The causal relationship between pesticide and cutaneous neoplasms has been the subject of many studies, such as those of Gallagher et al. (28), Robinson et al. (29), Krishnatreya et al. (30), Brouwer et al. (31), demonstrating the impact of pesticide on skin cancer. In line with literature evidence, our results revealed that dimethoate increased COX-2 expression in rat skin. However, in the literature, there is an absolute scarcity of experimental studies, using animal model, associating the UV and pesticide variables (32). Interestingly, our results demonstrated that the combination of UV-B and dimethoate decreased COX-2 immunoexpression. Such findings are very new and so, difficult to explain. Further studies are welcomed to elucidate the issue.

In summary, our results suggest that exposure to UV-B and dimethoate is able to induce histopathological changes in rat skin and altered expression of cleaved caspase- 3 and $\mathrm{Ki}-67$. Such results are considered as a risk condition for carcinogenesis, in Wistar rats. The causal association between exposure to both pesticide and UV radiation and the onset of skin cancer, despite being strongly emphasized, requires further studies to be fully understood.

\section{Conflicts of Interest}

The Authors declare no conflicts of interest.

\section{Authors' Contributions}

Research project conception: TMROF, JPK and HP. Study design: TMROF, JPK, CTFO, LK and MSS. Data analysis: TMROF, CTFO, DAR and HP. Writing of the manuscript: all Authors.

\section{Acknowledgements}

DAR is a researcher on Productivity at $\mathrm{CNPq}$ (Conselho Nacional de Desenvolvimento Cientifico e Tecnologico; grant number \#001).

\section{References}

1 International Agency for Research on Cancer. IARC. Available from: https://publications.iarc.fr/Book-And-Report-Series/IarcMonographs-On-The-Identification-Of-Carcinogenic-HazardsTo-Humans/Some-Organochlorine-Pesticides-1974 (last accessed July, 5, 2019)

2 Thorn $\mathrm{J}$ and Kerekes E: Health effects among employees in sewage treatment plants: A literature survey. Am J Ind Med 40(2): 170-179, 2001. PMID: 11494345.

3 Instituto Nacional de Câncer José Alencar Gomes da Silva. Coordenação de Prevenção e Vigilância. Estimativa 2016: incidência de câncer no Brasil/Instituto Nacional de Câncer. José Alencar Gomes da Silva - Rio de Janeiro: INCA, pp: 1-130, 2015.

4 Yeager DG and Lim HW: What's new in photoprotection: A review of new concepts and controversies. Dermatol Clin 37(2): 149-157, 2019. PMID: 30850037. DOI: 10.1016/j.det.2018. 11.003

5 Bottomley MJ, Thomson J, Harwood C and Leigh I: The role of the immune system in cutaneous squamous cell carcinoma. Int J Mol Sci 20(8): E2009, 2019. PMID: 31022866. DOI: 10.3390/ ijms20082009 
6 Marrot L and Meunier JR: Skin DNA photodamage and its biological consequences. J Am Acad Dermatol 58(5 Suppl 2): S139-148, 2008. PMID: 18410800. DOI: 10.1016/j.jaad.2007. 12.007

7 Roy JS, Chatterjee D, Das N and Giri AK: Substantial evidences indicate that inorganic arsenic is a genotoxic carcinogen: a review. Toxicol Res 34(4): 311-324, 2018. PMID: 30370006 DOI: $10.5487 / T R .2018 .34 .4 .311$

8 Rafnsson V: Risk of non-Hodgkin's lymphoma and exposure to hexachlorocyclohexane, a nested case-control study. Eur J Cancer 42(16): 2781-2785, 2006. PMID: 16934973.

9 Kier LD: Review of genotoxicity biomonitoring studies of glyphosate-based formulations. Crit Rev Toxicol 45(3): 209218, 2015. PMID: 25687244. DOI: 10.3109/10408444. 2015.1010194

10 Claudio SR, Simas JMM, Souza ACF, DO Carmo Baracho DE, Alencar M, Yamauchi LY and Ribeiro DA: Genomic instability and cytotoxicity in buccal mucosal cells of workers in banana farming evaluated by micronucleus test. Anticancer Res 39(3): 1283-1286, 2019. PMID: 30842159. DOI: 10.21873/anticanres. 13239

11 La Merrill M, Emond C, Kim MJ, Antignac JP, Le Bizec B, Clément K, Birnbaum LS and Barouki R: Toxicological function of adipose tissue: focus on persistent organic pollutants. Environ Health Perspect 121(2): 162-169, 2013. PMID: 23221922. DOI: $10.1289 /$ ehp. 1205485

12 Haenen C, de Moor A and Dooms-Goossens A: Contact dermatitis caused by the insecticides omethoate and dimethoate. Contact Dermatitis 35(1): 54-55, 1996. PMID: 8896965. DOI: 10.1111/j.1600-0536.1996.tb02276.x

13 Schena D and Barba A: Erythema-multiforme-like contact dermatitis from dimethoate. Contact Dermatitis 27(2): 116-117, 1992. PMID: 8896965. DOI: 10.1111/j.1600-0536.1996. tb02276.x

14 Burns EM, Tober KL, Riggenbach JA, Schick JS, Lamping KN, Kusewitt DF, Young GS and Oberyszyn TM: Preventative topical diclofenac treatment differentially decreases tumor burden in male and female Skh-1 mice in a model of UVB-induced cutaneous squamous cell carcinoma. Carcinogenesis 34(2): 370-377, 2013. PMID: 23125227. DOI: 10.1093/carcin/ bgs349

15 Wulff BC, Thomas-Ahner JM, Schick JS and Oberyszyn TM: Celecoxib reduces the effects of acute and chronic UVB exposure in mice treated with therapeutically relevant immunosuppressive drugs. Int J Cancer 126(1): 11-18, 2010. PMID: 19609953. DOI: 10.1002/ijc.24749

16 Tang X, Kim AL, Kopelovich L, Bickers DR and Athar M: Cyclooxygenase-2 inhibitor nimesulide blocks ultraviolet Binduced photocarcinogenesis in SKH-1 hairless mice. Photochem Photobiol 84(2): 522-527, 2008. PMID: 18266822. DOI: $10.1111 / \mathrm{j} .1751-1097.2008 .00303 . x$

17 Elmore SA, Dixon D, Hailey JR, Harada T, Herbert RA, Maronpot RR, Nolte T, Rehg JE, Rittinghausen S, Rosol TJ, Satoh H, Vidal JD, Willard-Mack CL and Creasy DM: Recommendations from the INHAND Apoptosis/Necrosis Working Group. Toxicol Pathol 44(2): 173-188, 2016. PMID: 26879688. DOI: $10.1177 / 0192623315625859$

18 Barrezueta LF, Oshima CT, Lima FO, De Oliveira Costa H, Gomes TS, Neto RA and De Franco MF: The intrinsic apoptotic signaling pathway in gastric adenocarcinomas of Brazilian patients: Immunoexpression of the Bcl-2 family (Bcl-2, Bcl-x,
Bak, Bax, Bad) determined by tissue microarray analysis. Mol Med Rep 3(2): 261-267, 2010. PMID: 21472231. DOI: 10.3892/ mmr_00000249

19 Dainichi T, Amano S, Matsunaga Y, Iriyama S, Hirao T, Hariya T, Hibino T, Katagiri C, Takahashi M, Ueda S and Furue M: Chemical peeling by SA-PEG remodels photo-damaged skin: suppressing p53 expression and normalizing keratinocyte differentiation. J Invest Dermatol 126(2): 416-421, 2006. PMID: 16374463. DOI: 10.1038/sj.jid.5700066

20 Smoller BR: Squamous cell carcinoma: from precursor lesions to high-risk variants. Mod Pathol 2006; 19(2): S88-92, 2006. PMID: 16446718.

21 Spiewak R: Pesticides as a cause of occupational skin diseases in farmers. Ann Agric Environ Med 8(1): 1-5, 2001. PMID: 11426918.

22 Salama SA, Arab HH, Omar HA, Gad HS, Abd-Allah GM, Maghrabi IA and Al Robaian MM: L-carnitine mitigates UVAinduced skin tissue injury in rats through downregulation of oxidative stress, p38/c-Fos signaling, and the proinflammatory cytokines. Chem Biol Interact 285: 40-47, 2018. PMID: 29499191. DOI: 10.1016/j.cbi.2018.02.034

23 Otkur W, Liu W, Wang J, Jia X, Huang D, Wang F, Hayashi T, Tashiro SI, Onodera S and Ikejima T: Sub-lethal ultraviolet B irradiation and Poly I:C treatment synergistically induced apoptosis of HaCaT cells through NF-kB pathway. Mol Immunol 99: 19-29, 2018. PMID: 29674236. DOI: 10.1016/ j.molimm. 2018.04.001

24 Terra VA, Souza-Neto FP, Frade MA, Ramalho LN, Andrade TA, Pasta AA, Conchon AC, Guedes FA, Luiz RC, Cecchini R and Cecchini AL: Genistein prevents ultraviolet B radiation-induced nitrosative skin injury and promotes cell proliferation. J Photochem Photobiol B 144: 20-27, 2015. PMID: 25668145. DOI: $10.1016 /$ j.jphotobiol.2015.01.013

25 Kong P, Wu R, Liu X, Liu J, Chen S, Ye M, Y C, Song Z, He W, Yin C, Yang Q, Jiang C, Liao F, Peng R, Zhou Z, Xu C and Xia L: The effects of anti-inflammatory drug treatment in gastric cancer prevention: an update of a meta-analysis. J Cancer 7(15): 2247-2257, 2016. PMID: 27994661. DOI: $10.7150 /$ jca. 16524

26 Jiao J, Mikulec C, Ishikawa TO, Magyar C, Dumlao DS, Dennis EA, Fischer SM and Herschman H: Cell-type-specific roles for COX-2 in UVB-induced skin cancer. Carcinogenesis 35(6): 1310-1319, 2014. PMID: 24469308. DOI: 10.1093/carcin/ bgu020

27 Nijsten T, Colpaert CG, Vermeulen PB, Harris AL, Van Marck $\mathrm{E}$ and Lambert J: Cyclooxygenase-2 expression and angiogenesis in squamous cell carcinoma of the skin and its precursors: a paired immunohistochemical study of 35 cases. $\mathrm{Br}$ J Dermatol 151(4): 837-845, 2004. PMID: 15491425. DOI: 10.1111/j.1365-2133.2004.06214.x

28 Gallagher RP, Macarthur AC, Lee T K, Weber JP, Leblanc A, Mark Elwood J, Borugian M, Abanto Z and Spinelli JJ: Plasma levels of polychlorinated biphenyls and risk of cutaneous malignant melanoma: a preliminary study. Int J Cancer 128(8): 1872-1880, 2011. PMID: 20533551. DOI: $10.1002 / \mathrm{ijc} .25503$

29 Robinson SN, Zens MS, Perry AE, Spencer SK, Duell EJ and Karagas MR: Photosensitizing agents and the risk of nonmelanoma skin cancer: A population-based case-control study. J Invest Dermatol 133: 1950-1955, 2013. PMID: 23344461 
30 Krishnatreya M, Kataki AC, Sharma JD and Lahkar K: A retrospective analysis of occupational exposure to pesticides as a possible risk factor for non-melanoma skin cancers. South Asian J Cancer 4(1): 47-48, 2015. PMID: 25839025. DOI: 10.4103/2278-330X.149955

31 Brouwer M, Schinasi L, Beane Freeman LE, Baldi, I, Lebailly P, Ferro G, Nordby KC, Schüz J, Leon ME and Kromhout H: Assessment of occupational exposure to pesticides in a pooled analysis of agricultural cohorts within the AGRICOH consortium. Occup Environ Med 73(6): 359-367, 2016. PMID: 27009271 .
32 Wang Y, Zhou X, Weinstein E, Maryles B, Zhang Y, Moore J, Gao D, Atencio DP, Rosenstein BS. Lebwohl M, Chen HD, Xiao T and Wei H: P53 gene mutations in SKH-1 mouse tumors differentially induced by UVB and combined subcarcinogenic benzo[a]pyrene and UVA. Photochem Photobiol 84(2): 444-449, 2008. PMID: 18248503. DOI: 10.1111/j.1751-1097.2007. 00282.x

Received July 10, 2019

Revised August 7, 2019 Accepted August 8, 2019 